\title{
OVER DE THEORIE DER ECONOMISCHE POLITIEK
}

Door Prof. Dr J. TINBERGEN

1. In het Februari-nummer van dit tijdschrift heeft de heer Houthakker een artikel aan bovenstaand onderwerp gewijd ${ }^{\mathrm{I}}$ ) waarin hij mijn boekje van gelijke titel bespreekt. Gaarne ga ik op het aanbod van de redactie in, op deze bespreking een wederwoord te doen volgen: het belang van de door de schrijver gemaakte opmerkingen zou reeds een voldoende verontschuldiging zijn.

Een eerste opmerking heeft betrekking op de geringe betrouwbaarheid van de in de modellen gebruikte coëfficiënten. Ik wil deze betrouwbaarheid niet als zeer groot voorstellen; doch ik ben sterk geneigd deze en enkele der volgende vragen vanuit een gezichtspunt te bezien, dat aandacht schenkt aan de alternatieve methoden die we hebben om de ons door de practijk gestelde problemen te behandelen. In dat opzicht verwijder ik mij dus bewust van het adagium, waarmede Prof. Houthakker aan het einde van zijn betoog het geheel nog eens belicht: „bij twijfel, onthoudt u". Als deze onthouding tot gevolg heeft dat nog primitievere methoden worden gebruikt tot het bespreken der economisch-politieke vraagstukken, meen ik mij niet te moeten onthouden. Wat bedoel ik met "nog primitievere methoden"? De methoden van de redenering in woorden, gesteund door statistische cijfers, met de bedoeling om de globale interrelaties in het economische leven tot gelding te brengen. De methoden dus ter vervanging van het econometrische model; niet de methoden ter aanvulling van het model, want die zijn nodig en gewenst zowel indien het model wel gebruikt wordt als indien het niet wordt gebruikt.

1) H. S. Houthakker, Het mechanisme der economische politiek, De Economist (1954) blz. 93 e.v. 
Men zou de betekenis van de econometrische modellen, zoals ik die thans zie, als volgt kunnen aanduiden. Zij trachten in logisch consistente vorm de meningen van de economen over de voornaamste betrekkingen in de volkshuishouding weer te geven. De cijfers hebben allereerst de pretentie met de werkelijkheid niet in flagrante strijd te zijn. Daarmee is al zeer veel gewonnen in vergelijking tot de niet-wiskundige methoden. Wil men verder gaan en maatstaven voor de statistische betrouwbaarheid aanleggen, dan zal menigmaal blijken dat deze nog weinig tot ons inzicht kunnen bijdragen: de onzekerheidsgrenzen op deze wijze verkregen zijn vaak wijder dan de onzekerheidsgrenzen die ons economisch inzicht ons doen zien. Ik ben dus met Houthakker eens dat in dit opzicht nog zeer grote twijfel gerechtvaardigd is; doch deze kan soms door gebruikmaking van afzonderlijke structuurstudies verminderd worden, en evenzeer door het opstellen van economische hypotheses, of door combinatie van beide. Een voorbeeld is de coëfficiënt van de marginale uitgavequote, door mij voor niet-arbeiders-inkomens op 0.7 gesteld. Dit getal kan gemotiveerd worden door (a) de hypothese dat alle inkomensverhoging wordt uitgegeven, nadat voor belasting is gereserveerd en (b) een afzonderlijke structuurstudie die de marginale belastingdruk bepaalt. Voor verschillende andere coëfficiënten zijn soortgelijke motiveringen te geven, b.v. voor de coëfficiënt die de invloed van het loonpeil op de prijzen weergeeft.

De genoemde onzekerheden zijn overigens aanleiding geweest om bij de toepassingen niet te werken met slechts één waarde voor elke coëfficiënt, doch veelal met verschillende alternatieve waarden, die achtereenvolgens werden toegepast. Men zal hiervan voorbeelden kunnen vinden in hoofdstuk VIII van mijn werkje „Econometrics”, dat als een voorloper van het hier beschouwde boekje kan worden beschouwd.

2. Een tweede bedenking van mijn criticus richt zich tegen het gebruik van lineaire vergelijkingen. Hier kan mijn antwoord kort zijn. Er is bij het werken met zulke eenvoudige vergelijkingen als door mij gebruikt weinig bezwaar tegen het introduceren van niet-lineaire vergelijkingen. Doch het is maar zelden zo, dat een macro-economische vergelijking bij statistische toetsing blijkt een duidelijk kromlijnig karakter te bezitten. Men moet de 
gevallen met een lantaarntje zoeken ${ }^{2}$ ). Overigens is men bij kleine afwijkingen van de uitgangstoestand altijd gerechtigd om een rechtlijnig verband aan te nemen, hetgeen in een reeks der beschouwde problemen reeds voldoende is; met name wanneer het gaat om een negatief antwoord op de vraag of een kleine verandering in een bepaald instrument voldoende is om een gewenste verandering in een der doelvariabelen te bewerken.

3. De heer Houthakker heeft ook zekere bezwaren tegen de gebezigde theorie, die hij als wat te Keynesiaans en op de depressiejaren afgestemd beschouwt; een te geringe nadruk op monetaire factoren valt hem op. Indien hiermede bedoeld is, dat met verschijnselen kenmerkend voor een toestand van volledige werkgelegenheid of volledig gebruik der capaciteit weinig rekening is gehouden, kan worden geantwoord dat deze verschijnselen toch niet verwaarloosd zijn. Aangenomen is dat een verhoging van de gevraagde hoeveelheid op het prijsniveau verhogend werkt, hetgeen in de eenvoudigste depressiemodellen der Keynesianen niet wordt gedaan. De coëfficiënt $\pi_{2}$, die de intensiteit aangeeft waarmede de prijzen reageren, is gebaseerd op het prijsgedrag in de jaren ' 20 en ' 30 en zou dus als te laag kunnen worden beschouwd. Daarom is onder de alternatieven die naast de gepubliceerde nog zijn berekend er ook een beschouwd waarbij deze coëfficiënt verdubbeld werd; de invloed daarvan was echter niet zeer groot.

Dat aldus geen sterke invloed van de bezettingsgraad van het bedrijfsleven op het prijspeil werd gevonden kan wellicht nog worden verklaard uit het feit dat Nederland een klein land is. Het prijspeil in een klein land wordt in hoge mate door de wereldmarkt bepaald. Een daar aanwezige inflatoire toestand - hoe ook gedefinieerd - zal ook reeds de invoerprijzen van het kleine land opgedreven hebben. Een in het kleine land zelf aanwezige inflatoire toestand werkt meer op het betalingsbalanstekort dan op het prijspeil. De heer Houthakker schijnt dit ook te hebben gezien, wanneer hij constateert: „Overigens ligt de klemtoon in

2) Hoe moeilijk het is om van zelfs evidente knelpunten de kromlijnige aanbodcurven te ontdekken toont het artikel van Mej. $\mathrm{H}$. Goris en de heer L. M. Koyck: „Prices of investment goods and the volume of production in the United States", Review of Economics and Statistics, Febr. 1953. 
de voorbeelden op betalingsbalansproblemen op korte termijn, die zich blijkbaar goed voor behandeling met de besproken eenvoudige modellen lenen".

4. „De critiek die in de voorafgaande alinea ligt besloten richt zich tegen het statische karakter van de onderhavige theorie" is het volgende punt. Naar het mij voorkomt is dit echter grotendeels het gevolg van het feit dat ik mij als vraagstuk steeds in overeenstemming met de taak van het Centraal Planbureau - heb gesteld: wat moet er in het volgend jaar worden gedaan? Het probleem heeft daardoor betrekking op slechts één tijdseenheid. Ook wanneer men een dynamisch stelsel van vergelijkingen gebruikt ter beschrijving der economische banden, wordt het vraagstuk daardoor statisch. Als de uitgaven voor investeringen $I_{t}$ in het planjaar $t$ b.v. geacht worden af te hangen van het inkomen $Y_{t}$ in het planjaar en dat in het jaar $t-1$, dan is in de formule

$$
I_{t}=\eta_{1} Y_{t}+\eta_{2} Y_{t-1}
$$

de laatste term gegeven en blijft slechts een statisch vraagstuk over. Dit wordt natuurlijk anders wanneer men zich verdiept in een ontwikkeling over meerdere tijdseenheden; en men zal dan ook zowel bij de modellen voor de ontwikkeling op langere termijn als bij die voor de conjunctuurpolitiek trekken vinden die meer aansluiten bij wat zich Prof. Houthakker heeft voorgesteld. Dat intussen door dit statische karakter van het model de gevoerde politiek achter de feiten zou aanlopen - zoals mijn opponent verder betoogt - is mij niet duidelijk. Er wordt op twee wijzen getracht met toekomstige situaties reeds bij voorbaat rekening te houden: ten eerste, door gebruik te maken van de vertragingen in de relaties als hierboven beschreven en ten tweede door, zoals de heer Houthakker reeds zelf vermeldt, het schatten van toekomstige waarden der data - niet alleen door extrapolatie. Voorzover er achter de feiten wordt aangelopen en dat gebeurt natuurlijk toch vaak - is dit niet aan het "statische karakter" van het model toe te schrijven, maar aan het optreden van buiten-economische storingen en aan onze beperkte kennis van het economisch mechanisme in het algemeen. 
5. Bij een bespreking van de door mij gehanteerde begrippen „instrumenten" en "doelstellingen" der economische politiek staat Prof. Houthakker allereerst stil bij de vraag of er een "collectieve voorkeursfunctie" is, die als basis van de doelstellingen kan worden beschouwd. Hij herinnert er aan dat de mening thans vrijwel algemeen aanvaard wordt dat een zodanige collectieve voorkeursfunctie niet kan worden geconstrueerd uit de individuele voorkeursfunctie der burgers. Bij deze mening sluit ik mij gaarne in de zin als dat bedoeld is door Arrow ${ }^{3}$ ). Ik heb mij op een ander standpunt willen plaatsen; theoretisch, door aan te nemen dat er een voorkeursfunctie ,van de regering" zou zijn, die men empirisch zou kunnen vaststellen door „de regering" te ondervragen. Voor de practijk van de economische politiek op korte termijn heb ik nog een verdere stap gedaan door - in de in dit boekje behandelde voorbeelden - zelfs aan te nemen dat er een politiek van gefixeerde doelstellingen wordt gevolgd. Het komt mij voor dat dit de toestand hier te lande in de jaren sedert 1945 niet zo slecht weergeeft. Bij herhaling heeft de regering haar doelstellingen in quantitatieve vorm kenbaar gemaakt. Men denke aan de doelstellingen betalingsbalansevenwicht, hoge en stabiele werkgelegenheid (bij herhaling vertaald als ",niet meer dan $3 \%$ werkloosheid", hetgeen neerkomt op „ca. $3 \%$ werkloosheid”), een investeringsvolume als berekend in de Industrialisatienota's, militaire uitgaven als overeengekomen met de bondgenoten (de bekende $f$ 1,5 milliard per jaar) enz. Natuurlijk is het volkomen juist om voor een politiek op iets langere termijn een politiek met flexibele doelstellingen aan te nemen, waarbij ik in het bijzonder denk aan b.v. een maximum verbruik per hoofd onder zekere nevenvoorwaarden. Een iets algemenere opzet is dat een collectieve nutsfunctie wordt aangenomen die van meer dan een grootheid afhangt. In een binnenkort te publiceren tweede deeltje in dezelfde serie hoop ik een paar voorbeelflen van een dergelijke vorm van economische politiek te bespreken. Wil men het vraagstuk op die wijze behandelen, dan dient men echter gegevens te hebben of veronderstellingen te maken omtrent de relatieve waardering van de verschillende grootheden waarvan de nuttigheid afhangt. En deze

3) Kenneth J. Arrow: "Social Choice and Individual Values", Cowles Commission for Research in Economics, Monograph No. 12, New York and London, 1951. 
zal men dus door schatting of door enqueteren moeten verkrijgen.

Er blijft natuurlijk nog het vraagstuk in hoeverre nu een nutsfunctie van de regering inderdaad als een weerspiegeling van de nutsfuncties der burgers kan worden opgevat. In bepaalde opzichten is dat natuurlijk wel het geval; in andere even zeker niet. Ongetwijfeld liggen hier nog vele vraagstukken, zoals juist Arrow wel duidelijk heeft gemaakt. Men kan echter op de boven aangegeven wijze voor de practijk zeer nuttige partiële vraagstukken oplossen. En juist omdat het vraagstuk zoals Arrow het gesteld heeft onoplosbaar is, zal men zich in de practijk met andere, partiële oplossingen moeten behelpen. De behandelde kwesties b.v. van consistentie, randvoorwaarden e.d. zijn voor een zakelijke discussie vaak van grote betekenis.

Terecht herinnert de heer Houthakker er aan dat sommige der door mij gehanteerde doelvariabelen geen echte doelvariabelen zijn, zoals het betalingsbalansoverschot. Het verandert echter aan de probleemstelling natuurlijk niets of men de vergelijking $D=0$ een nevenvoorwaarde noemt dan wel een doelstelling. En veelal is een doelstelling op korte termijn een ,,instrument", echter niet in de betekenis die ik aan het laatste woord heb verbonden: een instrument is in mijn terminologie iets dat de regering zelf fixeert door een besluit. Zoiets kan men van het betalingsbalanstekort alleen maar zeggen bij volledige deviezenregulering.

6. Nadat mijn criticus aldus heeft betoogd dat het onderscheid tussen instrumenten en doelvariabelen niet vrij van willekeur is, vraagt hij zich af in hoeverre nu de gelijkheid in aantal dezer twee nu nog wezenlijke betekenis heeft. Daarmede raakt hij een punt aan dat ook in de discussie met andere vakgenoten reeds meermalen ter sprake is gekomen. De kern van wat ik hier meen te mogen stellen is duidelijk en eenvoudig: het is de gelijkheid van het aantal vergelijkingen en het aantal onbekenden, nodig om een vraagstuk oplosbaar te maken. De onbekenden zijn daarbij de waarden der instrumenten. Het aantal vergelijkingen na eliminatie van de ,irrelevante" grootheden - is het aantal vergelijkingen in het volledige stelsel, verminderd met het aantal der te elimineren irrelevante grootheden. Daar het aantal vergelijkingen in het volledige stelsel gelijk is aan het aantal econo- 
mische variabelen, dat weer gelijk is aan het aantal irrelevante grootheden plus het aantal der doelvariabelen, volgt hieruit dat het aantal vergelijkingen in het vereenvoudigde ,politieke" stelsel gelijk is aan het aantal doelstellingen.

Dit is, zoals gezegd, de kern, maar er zijn velerlei kanttekeningen bij nodig, die voor een groot deel ook reeds in mijn boekje zijn gemaakt.

Wat moet er gebeuren wanneer enkele instrumenten steeds alleen maar in een bepaalde combinatie voorkomen? Dan moet alleen deze combinatie als instrument worden geteld en slechts als éên enkel: men kan dan ook slechts te weten komen, hoeveel die combinatie in getallenwaarde moet zijn om aan de vergelijkingen te voldoen. Men kan dit in iets algemenere vorm aldus uitdrukken, dat slechts het aantal onafhankelijke instrumenten moet worden geteld; waarbij de onafhankelijkheid niet moet worden beoordeeld naar de mogelijkheid om ze in de practijk onafhankelijk van elkaar te wijzigen, maar naar de invloed die men met hen kan uitoefenen. Zolang men b.v. slechts met een macro-variabele voor alle verbruiksuitgaven tezamen werkt, zijn alle indirecte belastingen tezamen slechts als een enkel instrument aan te merken, omdat deze altijd slechts langs één weg invloed kunnen uitoefenen op de economische toestand en wel door hun totale hoogte. Eerst wanneer men verschillende onderdelen van het verbruik onderscheidt en daarvan aanneemt dat ze - b.v. - op het nationale inkomen een uiteenlopende invloed hebben, kan men ook zeggen, dat de onderdelen van de indirecte belastingen op verschillende wijzen de economische toestand kunnen beïnloeden en daarom als afzonderlijke instrumenten kunnen worden beschouwd. Men zal dus door van macro- op micromodellen over te gaan het aantal instrumenten aanzienlijk kunnen verhogen. Betekent dit dat men dan ook een veel groter aantal doeleinden kan nastreven? Dit is maar zeer ten dele het geval. Want naarmate men tot ",kleinere" instrumenten overgaat, is hun „reikwijdte” geringer. Met een partiële belasting als b.v. de tabaksaccijns kan men de toestand in de sigarenindustrie wel merkbaar beïnvloeden, maar niet de algemene bedrijvigheid. Daartoe zou men - theoretisch - dan zodanige verhogingen of verlagingen moeten toepassen, dat men ver boven de grenzen zou komen van wat op andere gronden toelaatbaar is. In de taal van mijn betoog: men zou er de randvoorwaarden mee over- 
schrijden. Het gehele hoofdstuk over de randvoorwaarden is dan ook bedoeld als een aanvulling op de eenvoudige stelling van de gelijkheid tussen aantal instrumenten en aantal doelstellingen; een aanvulling die uitzonderingen behandelt.

Evenzeer bestaat er een afzonderlijke situatie wanneer men een instrument toepast dat tevens doelvariabele is, een geval dat vaak in mondelinge discussies naar voren is gebracht ${ }^{4}$ ). Hier is de oplossing eenvoudig: een zodanig instrument is geen onbekende grootheid; om de overige instrumentwaarden te kunnen vastleggen moet men evenveel vergelijkingen hebben als het aantal der overige instrumenten bedraagt. Het aantal vergelijkingen is gelijk aan het aantal doelstellingen (na eliminatie van de irrelevante variabelen), inclusief de doelstelling die tevens instrument is. Deze laatste telle men dus als doelstelling en niet als instrument; zij is trouwens ook geen instrument in de strikte zin van ,een datum dat beïnloed kan worden”, omdat zij geen datum is - als men begrijpt wat ik bedoel!

7. Professor Houthakker meent dat mijn uitvoerige behandeling van de quantitatieve economische politiek - in vergelijking tot de summiere behandeling der qualitatieve - de indruk vestigt dat ik eerstgenoemde de meestbelovende acht. Terecht voegt hij daaraan toe: misschien onbedoeld; dit was nl. in het geheel niet de bedoeling. De verklaring is veeleer, dat onze economische en, ruimer, sociologische kennis der gedragingen der mensen nog zo beperkt is, dat slechts bij de behandeling der quantitatieve politiek althans enige kans op redelijke nauwkeurigheid van de uitkomsten bestaat. De kritiek van de heer Houthakker op de geringe nauwkeurigheid der uitkomsten, hierboven reeds onder 1. behandeld, accentueert dit alleen maar. Dienovereenkomstig was mijn boekje ook maar een greep en dat heb ik in de titel tot uitdrukking gebracht door het woordje ,on" te laten voorafgaan aan "the theory of economic policy". Er is nu overigens, zoals gezegd, een tweede deeltje ter perse, dat op enige vraagstukken van qualitatieve politiek ingaat en waarmede ik het evenwicht enigszins hoop te zullen herstellen. De criticus vergist zich wanneer hij de door mij behandelde politiek van interventie als „een politiek die althans gedeeltelijk op empirisch onderzoek is ge-

4) De eerste die dit onder mijn aandacht bracht was collega J. G. Koopmans. 
baseerd" stelt tegenover een politiek van onthouding. Ook deze laatste valt onder de behandelde onderzoekingen omdat zij door de waarde nul van een aantal instrumenten kan worden beschreven. Hij laat dan de opmerking volgen dat het geenszins vaststaat dat het verrichte onderzoek ,de waarde van vergaand overheidsingrijpen bevestigt”. „Zou men, om een voorbeeld te noemen, uit een vergelijking van de economische ontwikkeling in de verschillende landen na 1945 werkelijk kunnen concluderen dat de geleide economie veel tot herstel en vernieuwing heeft bijgedragen?"' zo vervolgt hij. Ik betwijfel met hem of deze conclusie nu reeds zou kunnen worden getrokken. Ons onderzoek zou daartoe zeker verder voortgeschreden moeten zijn. Ik zou reeds nu zelfs willen stellen dat men daarbij moet onderscheiden tussen verschillende soorten van ingrijpen. Mijn methode is ook bedoeld om - in zeer bescheiden mate - een bijdrage te leveren tot de keuze van de instrumenten: dat komt o.m. tot uitdrukking in mijn invoering van het begrip efficiëntie van een bepaald instrument met betrekking tot een bepaalde doelstelling. Uit de voorbeelden gegeven in „Econometrics”, heb ik b.v. de conclusie getrokken dat de prijspolitiek geen bijzonder nuttig instrument tot het beïnvloeden van het betalingsbalanssaldo zou zijn.

De theorie van de economische politiek, door Frisch in nieuwe banen geleid, zal er toe kunnen bijdragen de economische theorie zelf meer doelgericht te maken. Zij is echter nog in een beginstadium en er zal nog veel discussie nodig zijn om haar vastere inhoud te geven. De bijdrage tot de discussie die collega Houthakker heeft geleverd was daarbij zeer welkom. 